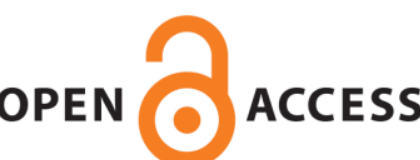

UWS Academic Portal

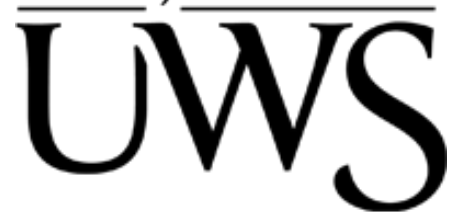

\title{
A cationic polymer enhanced PAC for the removal of dissolved aquatic organic carbon and organic nitrogen from surface waters
}

Wang, Chuang; Zhu, Guocheng; Ren, Bozhi; Zhang, Peng; Hursthouse, Andrew

Published in:

The Canadian Journal of Chemical Engineering

DOI:

$10.1002 /$ cjce.23234

Published: 21/05/2018

Document Version

Peer reviewed version

Link to publication on the UWS Academic Portal

Citation for published version (APA):

Wang, C., Zhu, G., Ren, B., Zhang, P., \& Hursthouse, A. (2018). A cationic polymer enhanced PAC for the removal of dissolved aquatic organic carbon and organic nitrogen from surface waters. The Canadian Journal of Chemical Engineering, 97(4). https://doi.org/10.1002/cjce.23234

\section{General rights}

Copyright and moral rights for the publications made accessible in the UWS Academic Portal are retained by the authors and/or other copyright owners and it is a condition of accessing publications that users recognise and abide by the legal requirements associated with these rights.

Take down policy

If you believe that this document breaches copyright please contact pure@uws.ac.uk providing details, and we will remove access to the work immediately and investigate your claim. 


\section{A cationic polymer enhanced PAC for the removal of dissolved aquatic}

\section{2 organic carbon and organic nitrogen from surface waters}

3

4 Chuang Wang ${ }^{1,2}$, Guocheng Zhu ${ }^{*}, 1,2,3$, Bozhi Ren ${ }^{1,2}$, Peng Zhang ${ }^{2}$, Andrew Hursthouse ${ }^{1,2,4}$

$6{ }^{1}$ Hunan Provincial Key Laboratory of Shale Gas Resource Utilization, Hunan University of Science and

7 Technology, Xiangtan 411201, China

$8 \quad{ }^{2}$ College of Civil Engineering, Hunan University of Science and Technology, Xiangtan 411201, China

$9{ }^{3}$ School of Resource Environment and Safety Engineering, Hunan University of Science and Technology,

10 Xiangtan 411201, China

$11{ }^{4}$ School of Science \& Sport, University of the West of Scotland, Paisley PA1 2BE UK

12 Corresponding author: Guocheng Zhu, email: zhuguoc@hnust.edu.cn; zgc945ahhn@163.com

\section{ABSTRACT:}

15 Dissolved organic carbon (DOC) and dissolved organic nitrogen (DON) are important

components of the aquatic environment and may produce harmful disinfection by-products through chlorination associated with water treatment processes. Therefore, it is necessary to remove them from the water. Coagulation is a cost-effective water treatment technique as the key unit in the pretreatment of drinking water but deals poorly with DON. We present a study to investigate the enhancement of poly aluminum chloride (PAC) using a cationic polymer for the removal of both DON and DOC. The cationic dimethyl diallyl ammonium chloride (PDMDAAC) polymer was hybridised with PAC to remove DON and DOC. The results showed that the PDMDAAC increased the charge neutralization capacity of PAC and floc aggregation thereby increasing the settling efficiency of flocs; the PDMDAAC increased the amount of colloidal species in PAC, which was beneficial to the formation of adsorption-bridging; with the increase 
26 of $\mathrm{pH}$, a greater proportion of colloidal adsorption sites were used in the removal of DON; the

27 DOC, DON and turbidity removal were dependent on multiple interactions through charge

28 neutralization, adsorption-bridging and floc sweeping. However, DOC and DON removal were

29 primarily determined by adsorption-bridging and floc sweeping, while turbidity removal was

30 mainly dependent on charge neutralization.

31 KEYWORDS: coagulation; dissolved organic nitrogen; dissolved organic carbon; Al-based 32 coagulation; cationic polymer

\section{INTRODUCTION}

35 Dissolved organic carbon (DOC) and dissolved organic nitrogen (DON) are important 36 components of dissolved organic matter (DOM) in aquatic environments ${ }^{[1]}$, soil environments ${ }^{[2]}$ 37 and other parts of surface environments ${ }^{[3 ; 4]}$. The DOC and DON are two different types of 38 organic compounds because DOC is made up of the hydrophobic fraction and high molar mass 39 compounds but the DON is characterized by small high molar mass compounds and hydrophilic 40 fractions ${ }^{[5]}$. The DOC accounts for large portion of DOM while DON only comprises a small 41 portion of DOM in surface water (about $0.5-10 \%$ by weight) ${ }^{[6]}$. Whilst DOC has been widely 42 studied, the academic community has only more recently shifted its focus to DON because of its 43 role in generating harmful nitrogen-based disinfection byproducts (N-DBPs), which have both 44 reproductive toxicity and carcinogenicity ${ }^{[7]}$. For example, DON has been identified as providing 45 most of the precursors needed to form N-nitrosodimethylamine (NDMA) ${ }^{[8]}$, thus contributing 46 much to NDMA formation ${ }^{[9]}$. Also, NDMA has been found to have a higher concentration than

47 other nitrosamines in drinking water ${ }^{[10]}$. Therefore, reducing NDMA concentration is essential to 48 the health of the world's population. The technology to control the content of the precursors will 
49 play a key role in lowering the content of disinfection byproducts. DON has also caused other 50 environmental issues such as membrane fouling ${ }^{[11]}$ and eutrophication ${ }^{[12]}$. Overall, to keep water

51 sources clean and quality reliable, we need to identify technologies that can treat contaminated 52 water and prevent further DON pollution.

54 Many methods have been used to treat DON pollution, these include examples of physical, 55 chemical and biological treatment processes ${ }^{[13]}$. Physical treatment includes adsorption ${ }^{[14]}$ and 56 membrane filtration ${ }^{[15]}$. Chemical treatment includes an advanced oxidation process ${ }^{[16]}$.

57 Researchers have tackled this problem with biological treatment, such as anaerobic microbial 58 digestion $^{[17]}$, use of algae ${ }^{[18 ; 19]}$, biological filtration ${ }^{[20]}$, and fixation within artificial wetland ${ }^{[21]}$.

59 For high quality potable water purification, adsorption materials are difficult to recycle. 60 Membrane fouling and operational costs need to be addressed. The advanced oxidation process is 61 expensive. Thus far, only hydrophilic DON has been effective for bioavailability reduction ${ }^{[22 ; 23]}$ 62 and the release of microbial products has possibly led to an increase in the levels of DON. From 63 the present treatment methods for DON removal from water and waste water, the treatment cost 64 and efficiencies are the core issues, thus for those plants using conventional water treatment 65 processes, the cost-effective and convenient treatment methods are the urgent requirement. 66 Coagulation is the most un-expensive process, which has long been the core unit in drinking 67 water plants. Effective coagulation has been beneficial to post-treatment processes, and has 68 improved water purification efficiency.

70 Unfortunately, the coagulation methods currently applied are not always effective for DON 71 removal. Compared to activated carbon, biological aerated filters and sand filters, coagulation has 
72 not been as effective in DON removal ${ }^{[24-25]}$, but is often effective for the hydrophobic fractions.

73 However, DON consists predominantly of hydrophilic fractions. A previous study showed that in

74 a wastewater treatment plant effluents, hydrophilic fractions in DON made up as much as $80 \%$ of

75 the water needing purification ${ }^{[22]}$. Effective DON removal by coagulation is lower when this

76 happens, with an average DON removal efficiency of only $20 \%$ found in 28 water treatment

77 plants in a study in the USA ${ }^{[24]}$. However, when the water samples included higher molecular

78 weight compounds, DOC has a larger removal efficiency and enhanced coagulation is not

79 effective for DON ${ }^{[27]}$. The recommended coupling processes are potassium

80 permanganate/coagulation ${ }^{[28]}$, coagulation/adsorption ${ }^{[29]}$, and ozone/coagulation ${ }^{[30]}$. It appears

81 that single coagulation is difficult to use for effective DON treatment.

83 Therefore it is critical that research focuses on the development of coagulants that can better

84 remove DON. In colloidal solutions, colloidal particles and coagulants have a wide variety of

85 physical and chemical species, and these are important factors that determine the nature of the

86 coagulation processes and its efficiency ${ }^{[31]}$. In the coagulation process, the coagulant species vary

87 on the basis of a range of characteristics. Varieties include aluminum, iron or hybrid inorganic-

88 organic coagulant function can be identified through a significant positive correlation with the

89 removal of pollutants such as DOC, UV254 and turbidity. Although previous research has

90 indicated that all types of coagulant species have affected DON removal ${ }^{[5]}$, their transformation

91 and interaction in different aquatic systems, and their correlation with DON removal has not been

92 addressed. Low removal of DON in the coagulation process has shown that the development of

93 coagulant species should be given more attention. Application of cationic polymers enhances

94 DON removal for inorganic coagulation but the mechanisms still need to be discussed ${ }^{[32 ; 33]}$. 
96 The coupling of aluminum sulfate coagulant and cationic poly dimethyl diallyl ammonium

97 chloride (PDMDAAC) could enhance the removal efficiency of DON but the absolute removal

98 will still not be high ${ }^{[32]}$. The selection of a coagulant type with an appropriate chemical species

99 has to date been missed ${ }^{[32]}$. The response of hydrophobic compounds are different from those of

100 the hydrophilic organic compounds during treatment, however, very few reports focus on the

101 flocculation differences between DON and DOC ${ }^{[26,5]}$. Research on the effect of coagulant

102 species and their role in the water environment towards more effectively removing pollutants

103 needs to focus on identifying the removal mechanisms between DON and DOC, with major

104 advantages in improving the safety of drinking water.

105

106 In this study, evaluation of the enhanced polymeric aluminum chloride (PAC) coagulation for

107 DON and DOC by cationic PDMDAAC was assessed as well as the coagulation differences

108 between the two contaminants. The study focused on employing reasons for enhanced

109 coagulation and mechanisms. The hybrid coagulant of PAC and PDMDAAC was prepared and

110 labeled as PAC-PDMDAAC. The variations of coagulant species in the presence/absence of

111 PDMDAAC as well as in the coagulation process was investigated. In addition, floc aggregation

112 and zeta potential analyses were also used to further the advancement of enhanced coagulation

113 mechanisms.

114

1152 MATERIALS AND METHODS

$116 \quad 2.1$ Materials

117 All reagents used in this study were of analytical grade and included reagents such as aluminum 
118 chloride (Tianjing Stellar Reagent Co., Ltd., China), sodium acetate (Sinopharm Chemical

119 Reagent Beijing Co., Ltd., China), hydrochloric acid (Zhuzhou XingKong Huabo Co., Ltd.,

120 China), sodium carbonate (Tianjin Institute of Chemical Reagents, China), phosphoric acid

121 (Hunan Huihong Reagent Co., Ltd., China), phenanthroline (Tianjin Kermel Chemical Reagent

122 Co., Ltd., China), hydroxylamine hydrochloride(Tianjin Fengchuan Chemical Reagent

123 Technology Co., Ltd., China), and ferron (8-hydroxy-7-iodoquinoline-5-sulfonic acid)

124 (Sinopharm Chemical Reagent Beijing Co., Ltd.,China). Commercial PDMDAAC (molecular

125 weight is one hundred thousand) with a 40\% cationic degree was purchased (Zouping Mingxing

126 Chemical Co. Ltd., Binzhou, China). A commercial humic acid was purchased from Aladdin

127 Industrial Corporation. All aqueous solutions were prepared with ultrapure water using an

128 ultrapure LBY-20 water purifier (Chongqing OWEN Science and Technology Co. Ltd.). The 129 glassware and other labware were acid-washed, rinsed thoroughly with deionized water, and dried 130 prior to use.

\subsection{Coagulant preparation and characterization}

133 Liquid coagulants were prepared in a water bath at a constant temperature of $90{ }^{\circ} \mathrm{C}$. First, $72.45 \mathrm{~g}$ 134 of aluminum chloride hexahydrate were dissolved with $75 \mathrm{~mL}$ of distilled water. Concentrated 135 phosphoric acid was subsequently added into the above solution with a predetermined molar ratio 136 of $n_{\mathrm{P}} / n_{\mathrm{Al}}=0.3$. After a reaction for 2 hours under a water bath at $90{ }^{\circ} \mathrm{C}$ with a stirring speed of $137300 \mathrm{rpm} / \mathrm{min}$, the sodium carbonate was then added with a predetermined molar ratio of $138 n_{\mathrm{OH}} / n_{\mathrm{Al}}=0.09$. After a reaction for 1 hour, a predetermined volume $(6 \mathrm{~mL})$ of PDMDAAC was 139 then added. The reaction solution continued to stir for 12 hours at a rapid speed of $1000 \mathrm{r} / \mathrm{min}$ at a 140 room temperature. Finally, a homogeneous liquid was generated, which was the hybrid coagulant 
141 referred to as PAC-PDMDAAC. After at least 24 hours of aging, the coagulant could be used for

142 water treatment. Without PDMDAAC, the prepared coagulant was an enhanced polymeric

143 aluminum chloride (PAC). The $\mathrm{Al}_{2} \mathrm{O}_{3}$ mass percent in $\mathrm{PAC}$ and the hybrid coagulant were

144 measured with an acid-base titration according to Chinese Standard GB 15892-2009. The results

145 showed the $\mathrm{Al}_{2} \mathrm{O}_{3}$ mass percent of $11.24 \%$ in PAC-PDMDAAC and $13.48 \%$ in PAC, which met

146 the requirement of Chinese Standard GB 15892-2009.

147

$148 \quad 2.3$ Water samples and coagulation test

149 Water samples collected for coagulation included artificial lake water, river water, wetland water,

150 wastewater plant effluent, artificial pool water, natural pool water, algal solution. The

151 characteristic parameters of the water samples are shown in Table 1. Artificial lake was located on

152 the Hunan University of Science and Technology campus. Other water samples were collected

153 around the campus except for algae suspension (Microcystis aeruginosa). Algae solution was

154 prepared in the laboratory.

Table 1 Characteristic parameters of water samples.

\begin{tabular}{lccccc}
\hline Water Type & $\mathbf{p H}$ & Turbidity (NTU) & $\mathbf{U V 2 5 4}\left(\mathbf{c m}^{-\mathbf{1}}\right)$ & $\mathbf{D O C}(\mathbf{m g} / \mathbf{L})$ & DON (mg/L) \\
\hline Upstream River water & 7.5 & 11.43 & 0.04 & 15.62 & 0.75 \\
Downstream River water & 7.7 & 9.52 & 0.03 & 15.11 & 0.73 \\
Wetland water & 7.4 & 7.67 & 0.08 & 21.95 & 0.81 \\
Wastewater plant effluent & 7.1 & 3.31 & 0.04 & 25.07 & 1.08 \\
Artificial Pool water & 8.6 & 32.40 & 0.12 & 23.29 & 0.77
\end{tabular}


Natural pool water

Algae solution

Artificial lake water
7.4

7.3

7.0-8.0
8.02

3.01

8-15
0.05

0.03

$<1.0$
19.48

27.40

8-16
0.60

0.97

$<1.0$
157

158

159

160

161

162 added to the water sample, the $\zeta$ value was immediately measured. Water samples were analyzed

175 after the samples were filtered through a membrane (pore size $=0.45 \mu \mathrm{m}$ ) except for turbidity and $176 \zeta$ values. 
178 Fluorescence spectra of water samples that were filtered with a membrane filter (ore size $=0.45$

$179 \mu \mathrm{m}$ ) was tested using a fluorescence spectrophotometer (FL4600, Hitachi High Technologies,

180 Tokyo, Japan). The fluorescence intensity of an ultra-pure water as a blank sample was subtracted

181 from water samples. The Rayleigh and Raman scatter were removed according to the method

182 shown in reference ${ }^{[34]}$. Fluorescence region integration (FRI) developed by Chen, et al. ${ }^{[35]}$,

183 divided two-dimensional fluorescence excitation region into five parts including aromatic

184 protein-like materials denoted as I, aromatic protein-like materials denoted as II, fulvic acid-like

185 materials denoted as III, soluble microbial metabolites denoted as IV, humic substance-like

186 denoted as V. The integral volume of each of the above fluorescence regions is calculated as $\phi$

187 which reflects the relative content of organic matter in the integral region. Their reduction rates

188 are determined by the subtraction of each part between that before coagulation and that after

189 coagulation. The integral volume value is expressed as follows.

190

$\phi_{i, n}=\alpha_{i} \int_{e x e m} I d \lambda_{e x} d \lambda_{e m}$

where $\phi_{i, n}\left(\right.$ au.nm $\left.{ }^{2}\right)$ is standard integral volume of $i^{\text {th }}$ fluorescence region; $\lambda_{e x}$ is the excitation

wavelength $(\mathrm{nm}) ; \lambda_{e m}$ is the emission wavelength $(\mathrm{nm}) ; I$ is fluorescence intensity value at

corresponding to $\lambda_{e x}$ and $\lambda_{e m} ; \alpha_{i}$ is the ratio of the integral volume of all regions and the integral

volume for the $i^{\text {th }}$ region.

A ferron-complexation timed spectrophotometric method denoted as the ferron method was used to investigate the species of coagulant in a solution based on the standard adsorption curves of the reaction between PAC, PAC-PDMDAAC and the ferron reagent. The ferron reagent was rapidly prepared: $0.5 \mathrm{~g}$ 8-hydroxy-7-iodoquinoline-5-sulphonic acid and $0.025 \mathrm{~g}$ phenanthroline were 
204 dissolved and diluted to $250 \mathrm{~mL}$ in a volumetric flask; $10 \mathrm{~g}$ hydroxylamine hydrochloride and 4 $205 \mathrm{~mL}$ of $6 \mathrm{~mol} / \mathrm{L} \mathrm{HCl}$ were dissolved and diluted to $100 \mathrm{~mL}$ in a volumetric flask; $58.04 \mathrm{~g}$ of 206 sodium acetate trihydrate were dissolved and diluted to $100 \mathrm{~mL}$. The above three kinds of 207 solutions were mixed and diluted to $500 \mathrm{~mL}$ in a volumetric flask; finally, the $\mathrm{pH}$ of solution was 208 adjusted to $\mathrm{pH} 5$ approximately. A preliminary test was conducted to investigate if the complex 209 reaction of the coagulant and ferron reagent could form a color complex. Both PAC-PDMDAAC 210 and PAC can react with the ferron reagent forming a color complex at the same characteristic 211 peak of $\lambda=362 \mathrm{~nm}$. The absorbance of the color complex solution in the presence of sodium 212 acetate solution $(35 \%, \mathrm{~m} / \mathrm{m})$ at $\mathrm{pH} 5$ was linear to $\mathrm{Al}$ concentration with a squared correlation 213 coefficient of 0.9996 in the $\mathrm{Al}$ range of $10^{-5}$ to $10^{-4} \mathrm{~mol} / \mathrm{L}$. The visible light absorbance was 214 measured as a function of time at $\lambda=362 \mathrm{~nm}$ to quantify the amount of hydrolytic species. Those species reacting with the ferron reagent within 1 min were monomeric species, denoted as $\mathrm{Al}_{\mathrm{a}}$.

216 Those species reacting to the ferron reagent during the next $4 \mathrm{hrs}$ were medium polymeric 217 species, denoted as $\mathrm{Al}_{\mathrm{b}}$. The results of a preliminary test determined that absorbance did not 218 increase after monitored for $4 \mathrm{hrs;}$ therefore, any species that remained unreacted after 4 hrs was a 219 colloidal species, denoted as $\mathrm{Al}_{\mathrm{c}}$. The total $\mathrm{Al}$ concentration was measured using the colorimetry 220 method ${ }^{[36]}$. Prior to the measurement, the sample was acidified to $\mathrm{pH}<2$ with concentrated nitric acid. The total $\mathrm{Al}$ species content was denoted as $\mathrm{A}_{\mathrm{T}}$. With the contents of $\mathrm{Al}_{\mathrm{a}}$ and $\mathrm{Al}_{\mathrm{b}}$ species, the content of $\mathrm{Al}_{\mathrm{c}}$ species was calculated by the following equation.

$$
\mathrm{Al}_{\mathrm{c}}=\mathrm{Al}_{\mathrm{T}}-\left(\mathrm{Al}_{\mathrm{a}}+\mathrm{Al}_{\mathrm{b}}\right)
$$




$$
q=\frac{C_{0}-C_{e}}{C_{0}} \times 100 \%
$$

230 where $q$ is the removal efficiency; $C_{0}$ and $C_{\mathrm{e}}$ are the initial concentration and final concentration 231 measured after coagulation, respectively.

233 Dynamic floc size was monitored using a Malvern Mastersizer 2000 laser diffraction instrument 234 (Malvern, UK) during floc formation, breakage and reformation. The median volumetric diameter $235\left(\mathrm{~d}_{50}\right)$ was denoted as floc size. Three parameters were used to assess the floc growth 236 characteristics, floc growth rate $\left(G_{r}\right)$, a strength factor $\left(S_{f}\right)$ and a recovery factor $\left(R_{f}\right){ }^{[37]}$. The 237 given $G_{r}, S_{f}$ and $R_{f}$ equations are as follows.

$$
\mathrm{G}_{\mathrm{r}}=\frac{\Delta \text { size }}{\Delta \text { time }}
$$

$$
\mathrm{S}_{\mathrm{f}}=\frac{\mathrm{d} 2}{\mathrm{~d} 1}
$$

$$
\mathrm{R}_{\mathrm{f}}=\frac{\mathrm{d} 3-\mathrm{d} 2}{\mathrm{~d} 1-\mathrm{d} 2}
$$

244 where $\triangle_{\text {size }}$ is the difference between minimum and maximum of median flocs size in the rapid 245 growth region of flocs, which corresponds to a time duration for rapid growth, $\triangle_{\text {time}} ; \mathrm{d}_{1}$ is the 246 average median floc size of the steady phase before breakage; $d_{2}$ is the median floc size after it 247 was subjected to high shear rate; the average median size, $\mathrm{d}_{3}$, is the average median floc size of 
248 the steady phase of flocs after floc breakage.

\section{RESULTS and DISCUSSION}

\subsection{The comparison between PAC and PAC-PDMDAAC}

252 After assessing the effect of coagulants on the removal of artificial lake water turbidity, the DOC and DON was investigated with the initial water $\mathrm{pH}$ at 7.0 in this study. The initial turbidity, DOC and DON concentration was $8.35 \mathrm{NTU}, 10.02 \mathrm{mg} / \mathrm{L}$ and $0.76 \mathrm{mg} / \mathrm{L}$, respectively.

PAC had a lower performance in the settling speed of colloids and in the removal efficiencies of

257 DON and DOC than PAC-PDMDAAC. Although the amount of residual turbidity with PACPDMDAAC was close to that with PAC after settling $30 \mathrm{~min}$ (as shown in Figure 1a), the turbidity reduction after settling before the first 15 mins at $6 \mathrm{~cm}$ below the surface of suspension went faster, showing a stronger settling speed with PAC-PDMDAAC (Figure 1b). The PACPDMDAAC had a better effect on DOC and DON removals than PAC (Figs. 1c and d) below 30 $\mathrm{mg} / \mathrm{L}$. The overdosing effect showed that coagulants can play an adsorption-bridging role between particles surfaces only when the coagulant concentration is sufficiently small compared with the amount of saturated adsorption points ${ }^{[38 ; 39]}$. With the excess dose, resulted in a deterioration of water quality as well as turbidity. Thus, DOC and DON removal efficiencies were decreased with PAC-PDMDAAC. This showed that adsorption-bridging is an important coagulation mechanism of PAC-PDMDAAC. The PAC-PDMDAAC achieved a better effect on

268 the removal of DOC and DON with a lower dose than PAC (Figure 1c). However, DON removal 269 behavior did not follow the DOC removal pattern. Hence, a lower coagulant dose was needed for the DON removal than that for the DOC removal (Figure 1d). 
(a)

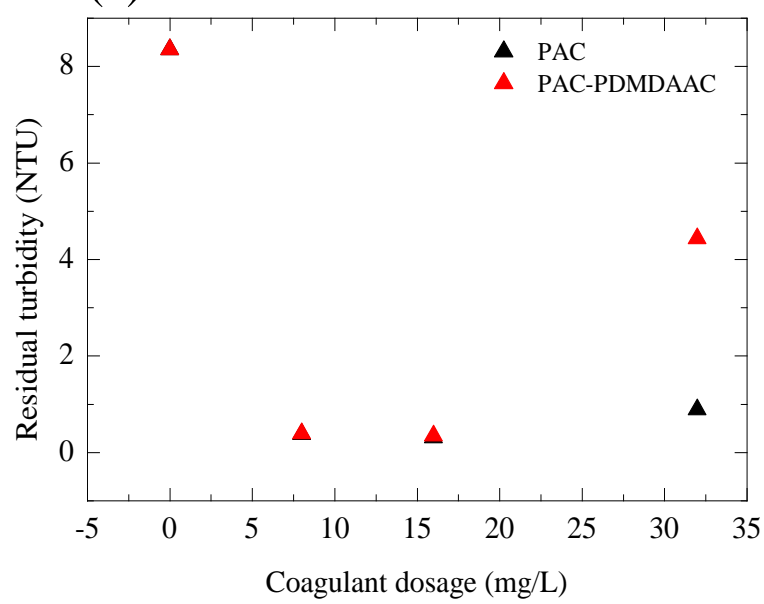

(c)

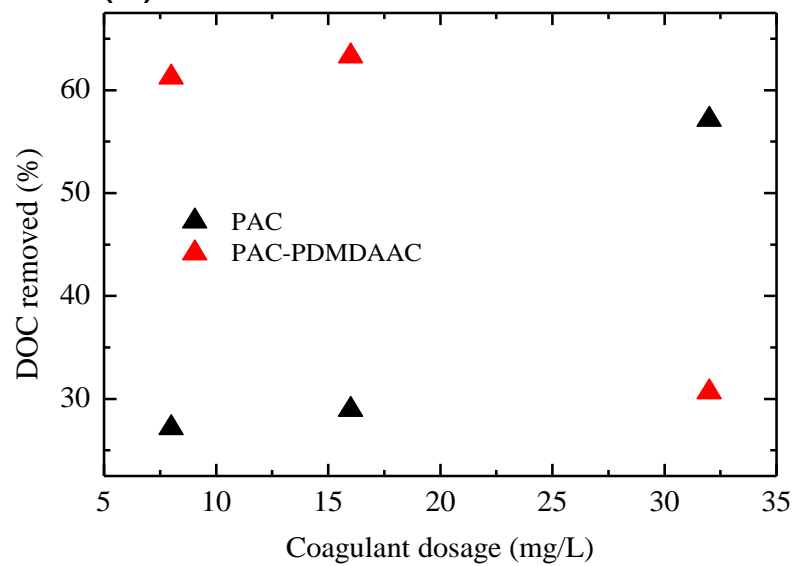

(b)

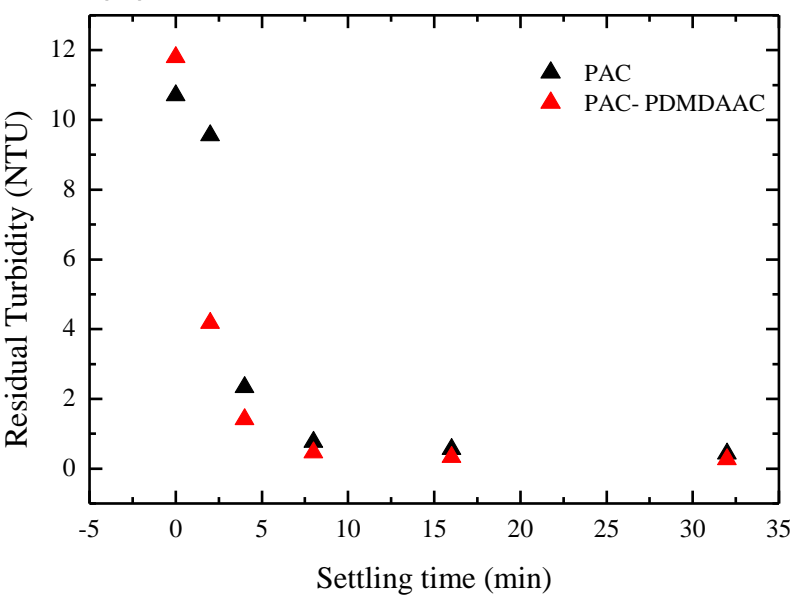

(d)

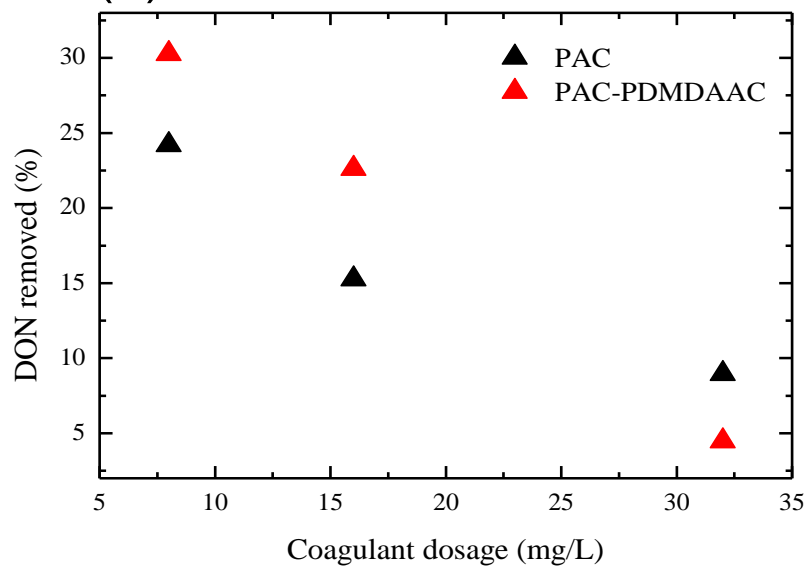

Figure 1 A comparison between PAC-PDMDAAC in: (a) turbidity removal which was recorded

275 after 30 min settling, (b) settling speed with coagulant dose of $20 \mathrm{mg} / \mathrm{L}$, (c) DOC removal which 276 was recorded after $30 \mathrm{~min}$ settling, and (d) DON removal which was recorded after 30 min 277 settling.

The effect of coagulant dose in the range of $5 \mathrm{mg} / \mathrm{L}$ to $30 \mathrm{mg} / \mathrm{L}$ on the removals of DON, DOC and turbidity was examined in this study using PAC-PDMDAAC. The initial artificial lake water $\mathrm{pH}$ was 7.0. The initial turbidity of DOC and DON were $14.3 \mathrm{NTU}, 14.4 \mathrm{mg} / \mathrm{L}$ and $0.61 \mathrm{mg} / \mathrm{L}$, 
283 respectively. The experimental results which were recorded after 30 min settling are shown in

284 Figure 2.

285

286 As seen from Figure 2a, the DOC removal followed the same trend as in the case of turbidity 287 reduction. At a coagulant dose of $20 \mathrm{mg} / \mathrm{L}$, the DOC and turbidity removals achieved the 288 maximum removal rate of $65.3 \%$ and $98.3 \%$, respectively. However, the turbidity removal was 289 different from DOC removal, its removal efficiency achieved the approximate maximum, 98.1\%, 290 with a lower coagulant dose of $10 \mathrm{mg} / \mathrm{L}$. The coagulant dose of $20 \mathrm{mg} / \mathrm{L}$ for DOC removal 291 efficiency could only be achieved at the maximum $65.3 \%$ turbidity removal rate. With the 292 coagulant dose increased from $5 \mathrm{mg} / \mathrm{L}$ to $20 \mathrm{mg} / \mathrm{L}$, both turbidity and DOC removal increased but 293 with an excess of $20 \mathrm{mg} / \mathrm{L}$, they both decreased. The main reason for the reduction was also 294 attributed to the overdosing effect. DON removal had a different characteristic from DOC and 295 turbidity removal efficiencies (Figure 2b). With the increase of coagulant dose over the range 296 investigated, the DON removal decreased. For a better removal of DON, a lower dose was 297 required compared to that for the enhanced removal of DOC and reduction in turbidity. 298

(a)

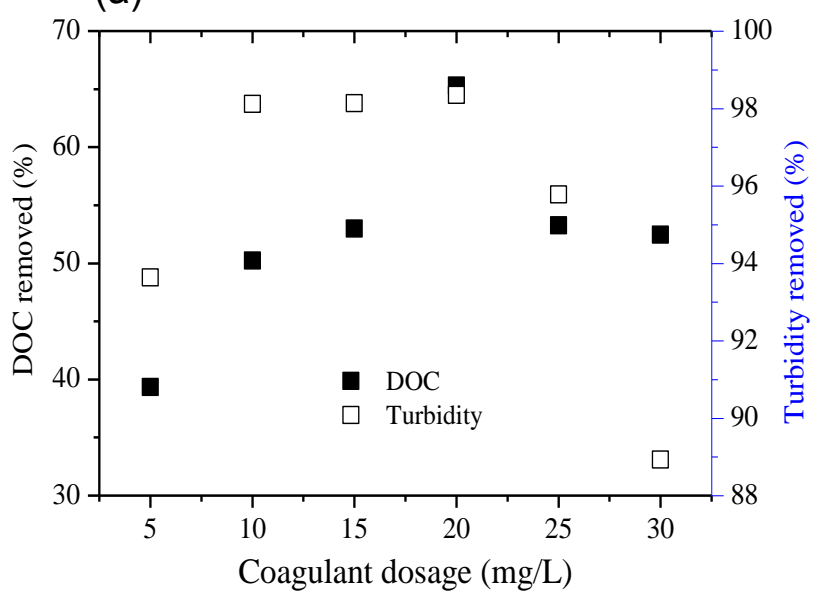

(b)

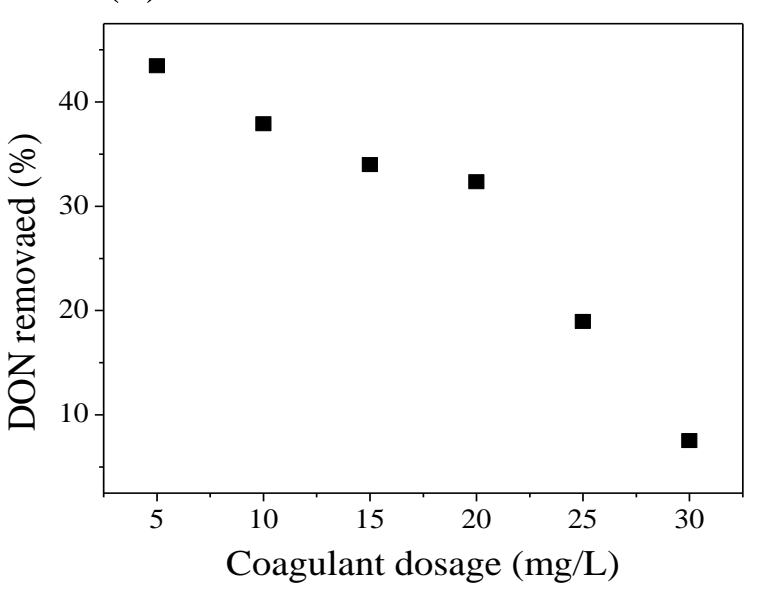



removals.

\section{$3.3 \mathrm{pH}$ effect}

305 The effect of initial artificial lake water $\mathrm{pH}$ in the range of 4 to 9 on the removals of DON, DOC and turbidity was investigated in this study using PAC-PDMDAAC. The coagulant dose of 20 $\mathrm{mg} / \mathrm{L}$ was used. The initial turbidity, DOC, and DON were $10.7 \mathrm{NTU}, 15.3 \mathrm{mg} / \mathrm{L}$ and $0.52 \mathrm{mg} / \mathrm{L}$, respectively. Experimental results which were recorded after $30 \mathrm{~min}$ settling are presented in 309 Figure 3.
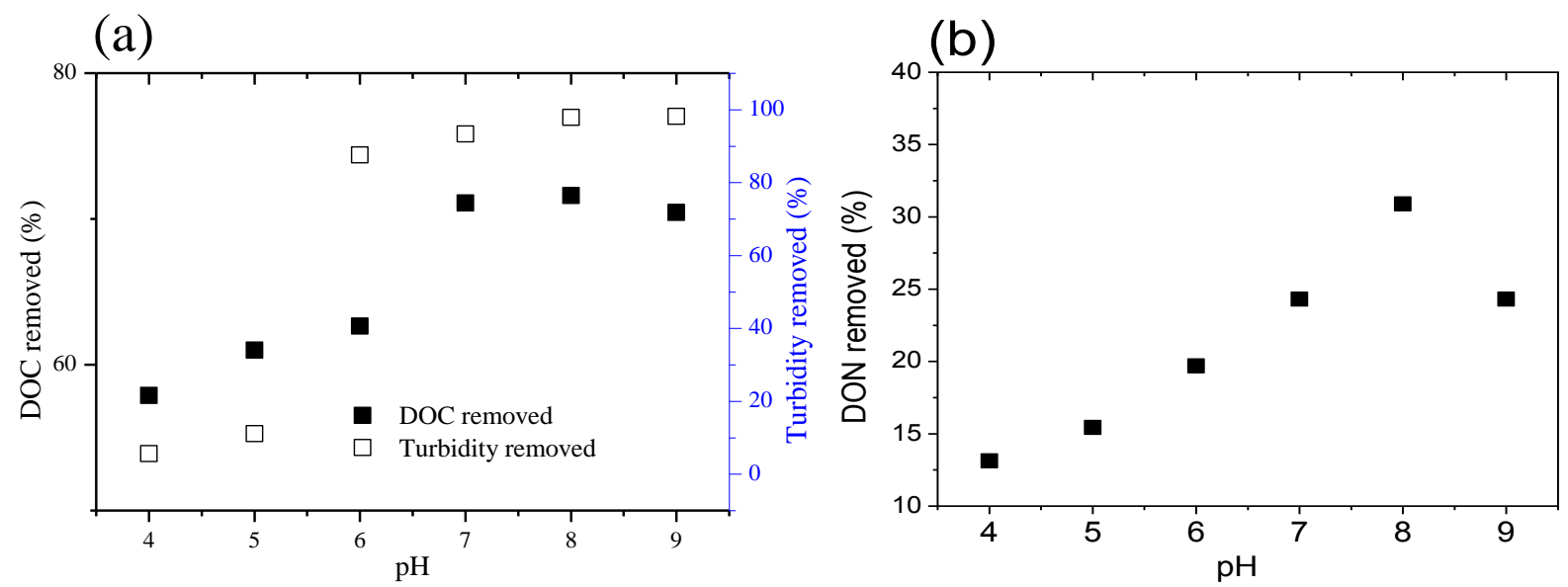

Figure 3 Effect of initial artificial lake water $\mathrm{pH}$ on (a) turbidity reduction and DOC removal and

As seen from Figure 3a, the reduction in turbidity increased with the increase of $\mathrm{pH}$. At $\mathrm{pH} 4$ and and at a higher $\mathrm{pH}$, the turbidity reduction efficiency still increased. At $\mathrm{pH} 8$ it achieved the approximate maximum, 97.9\%. The maximum removal efficiency, 98.13\%, was achieved at $\mathrm{pH}$

9. DON and DOC removal efficiencies achieved the maximum at $\mathrm{pH} 8$ (see Figures $3 \mathrm{a}$ and $\mathrm{b}$ ), but low efficiencies occurred at $\mathrm{pH} 4$ to 5 . Both removal efficiencies of DON and DOC increased 
with the increase of a $\mathrm{pH}$ below 8 because more amorphous $\mathrm{Al}(\mathrm{OH})_{3}$ formed to remove organic matter by adsorption during the precipitation of Al hydroxide flocs via flocs sweeping mechanism ${ }^{[40]}$. At $\mathrm{pH} 9$, more negatively charged $\mathrm{Al}(\mathrm{OH})_{3}$ flocs or $\mathrm{Al}(\mathrm{OH})_{4}{ }^{-}$ions formed, and the organic matter did not easily adsorb onto $\mathrm{Al}(\mathrm{OH})_{3}$ flocs or $\mathrm{Al}(\mathrm{OH})_{4}-$ due to the increased electrostatic repulsive force among colloids; resulting in decreased DON and DOC removal. Overall, the alkaline conditions were more suitable for reduction in turbidity.

\subsection{The enhanced floc aggregation}

328 The PAC, in the presence of PDMDAAC, provided better settling ability. The enhanced settling 329 performance was related to the cationic polymer effect on enhancing floc formation. Figure 4 330 shows the characteristics of floc formation. In the test, the PAC and PAC-PDMDAAC coagulant 331 dose were $20 \mathrm{mg} / \mathrm{L}$. The sample tested in this study was artificial lake with $\mathrm{pH}$ at 8.32 . The PAC332 PDMDAAC had a faster aggregation and settling performance as well as regrowth capacity. With 333 PAC and PAC-PDMDAAC, floc formation processes were different. With PAC-PDMDAAC, the 334 median floc size was significantly larger than that with PAC in the steady phase, and it had a 335 larger the $G_{r}$ value of $154.99 \mu \mathrm{m} / \mathrm{min}$, while with $P A C$, the $G_{r}$ value was $79.01 \mu \mathrm{m} / \mathrm{min}$. The 336 stronger $\mathrm{G}_{\mathrm{r}}$ value implies that PAC-PDMDAAC gave a faster aggregation and had a better 337 adsorption bridging performance ${ }^{[41]}$. PAC-PDMDAAC had a larger recovery factor of $16.27 \%$ 338 than that of $R_{f}=9.49 \%$ with PAC, which showed flocs have a better recovery capacity after 339 breakage. Floc strength was related to the number and strength of inter-particle bonds within flocs, 340 while the smaller flocs were more compact ${ }^{[41 ; 42]}$. In the presence of larger floc sizes, a lower resisting shear force accompanied PAC-PDMDAAC. The resistance of flocs to stress in the 342 presence of PDMDAAC was, therefore, possibly decreased. The strong factor of $34.67 \%$ tested in 
343 this study was slightly lower than that of PAC at $\mathrm{S}_{\mathrm{f}}=38.86 \%$. Overall, the above results showed 344 an effective hybrid effect in enhancing floc aggregation that possibly improves settling 345 performance.

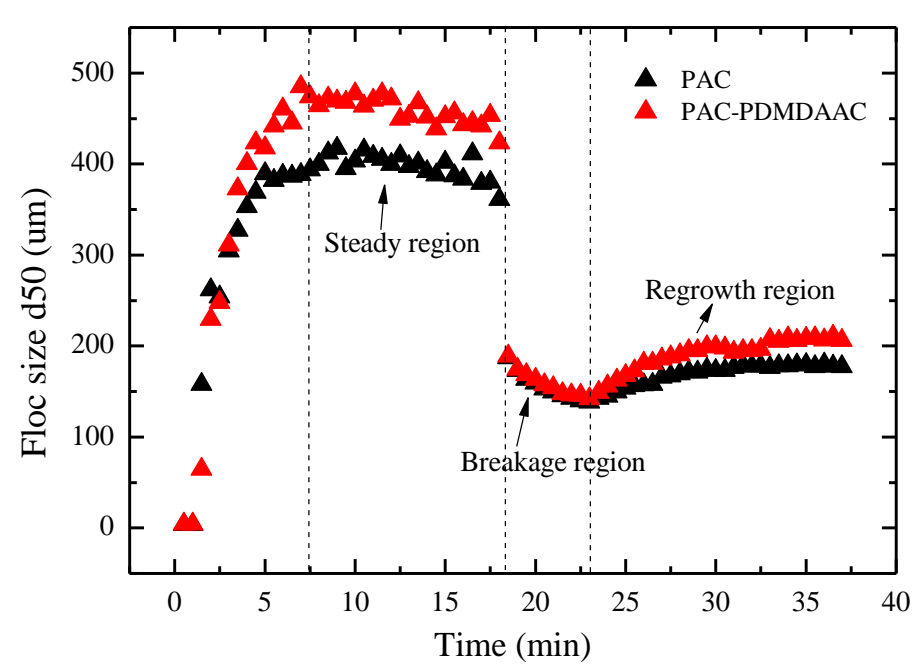

Figure 4 The growth, breakage and regrowth profiles of flocs with time.

\subsection{The enhanced charge neutralization capacity}

351 The presence of cationic PDMDAAC could increase the charge neutralization capacity of PAC 352 by assessing $\zeta$. With PAC and PAC-PDMDAAC, the $\zeta$ value was measured in the coagulation of 353 artificial lake water at an initial $\mathrm{pH}$ of 7.8 . The initial water $\zeta$ value was $-10 \mathrm{mV}$. The results are 354 presented in Figure 5a. Throughout the whole investigated dose of $4 \mathrm{mg} / \mathrm{L}$ to $16 \mathrm{mg} / \mathrm{L}$, with PAC355 PDMDAAC the $\zeta$ values were all higher than that with PAC. This indicates that the PDMDAAC 356 could help PAC improve charge neutralization capacity. The charge neutralization capacity was 357 also investigated through the $\mathrm{pH}$ effect on the $\zeta$ value with a coagulant dose at $20 \mathrm{mg} / \mathrm{L}$ as shown 358 in Figure 6b. It showed that PAC and PDMDAAC increased the $\zeta$ value with PAC at the same 359 tested $\mathrm{pH}$, which was less than 7.0. The $\zeta$ value with PAC-PDMDAAC decreased with the $\mathrm{pH}$, 
360 but it almost increased in a wide $\mathrm{pH}$ range (from 4.0 to 7.0 ). The main reason for $\zeta$ reduction from $361 \mathrm{pH} 8$ was attributed to the increase of negatively charged complexes of coagulants and organic 362 matter. The PDMDAAC, therefore, enhanced the neutralization capacity of PAC.

363

364 Zero potential appeared between $8 \mathrm{mg} / \mathrm{L}$ and $12 \mathrm{mg} / \mathrm{L}$ for PAC and PDMDAAC with a $\mathrm{pH}$ 365 between 5 and 6 for PAC. Better removal efficiencies of DOC and DON with PAC or PAC366 PDMDAAC did not appear at the near zero potential where charge neutralization was mostly 367 effective for removal of pollutants. Therefore, the dominant mechanism for the removal of 368 organic matter was not charge neutralization. On the contrary, efficient turbidity reduction 369 appeared around a zero potential at a coagulant dose of around $10 \mathrm{mg} / \mathrm{L}$ as seen from Figs. 5a; 370 thus, it showed its removal was dependent on charge neutralization. For a common coagulation

371 by charge neutralization, the effective $\mathrm{pH}$ range was found to be between 4.0 and $5.5^{[43]}$. At $\mathrm{pH}$, 372 most of turbidity could be removed with PAC-PDMDAAC with $\zeta<7 \mathrm{mV}$ (see Figure $3 \mathrm{a}$ and $5 \mathrm{~b}$ ). 373 With less coagulant dose, the $\zeta$ could be reduced to around zero potential point, and the turbidity 374 removal would be better. Therefore, it would reduce the amount of coagulant dose used in water 375 treatment. Under alkaline conditions, the PAC-PDMDAAC was also effective for turbidity 376 removal with a relatively higher removal value than that at $\mathrm{pH} 6$, which implies that floc 377 sweeping aids the charge neutralization to improve turbidity removal. 
(a)

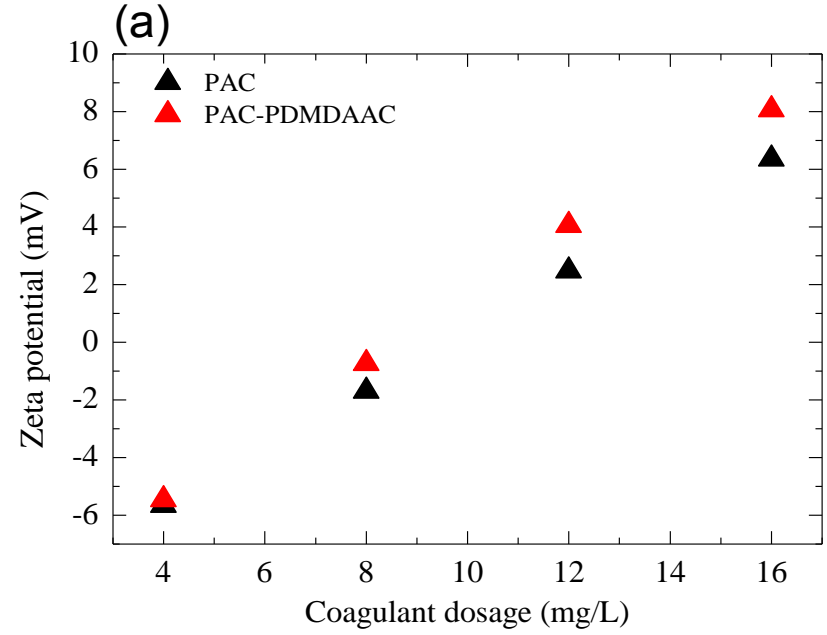

(b)

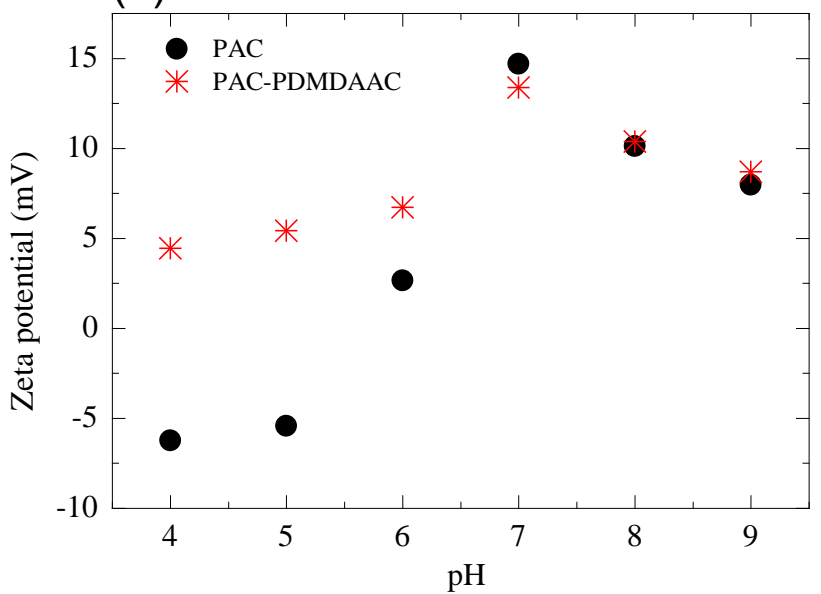

379

380

381

382

383

Figure 5 Zeta potential by varying (a) coagulant dose and (b) $\mathrm{pH}$ at coagulant dose of $20 \mathrm{mg} / \mathrm{L}$.

\subsection{The enhanced colloidal species}

The PAC-PDMDAAC had higher proportion of colloidal species. The colloidal species increased with the increase of PDMDAAC as shown in Figure 6a. The PAC-PDMDAAC included $n_{\mathrm{P}} / n_{\mathrm{Al}}$, $n_{\mathrm{OH}} / n_{\mathrm{Al}}=$ of $0.3,0.12$, respectively. The dose of PDMDAAC used was from $0 \mathrm{mg} / \mathrm{L}$ to $10 \mathrm{mg} / \mathrm{L}$.

The results showed that both monomeric species and medium polymeric species decreased with the increased proportion of colloidal species. The increase of colloidal species was conducive to adsorption bridging of organic matter. As shown in Table 2. The colloidal species in PACPDMDAAC found in this study was the highest, greater than that in PAC. The study of PAC showed the highest proportion of medium species, which was higher than that in PACPDMDAAC. Because the amount of monomeric species and medium species in PAC was both higher than that in PAC-PDMDAAC, in the presence of PDMDAAC, the medium species and monomeric species in PAC were transformed to colloidal species.

The influence of three kinds of species on removals of DON, DOC, and turbidity was different.

Medium species are considered capable of performing a dominant adsorption-bridging function in 
397 the removal of $\mathrm{DOM}$ (e.g., DOC and $\mathrm{UV}_{254}$ ), followed by the colloidal species and the 398 monomeric species ${ }^{[44 ; 45]}$. Other research ${ }^{[45]}$ has shown that the colloidal species play the 399 dominant role in adsorption-bridging of DOC and $\mathrm{UV}_{254}$, followed by the medium species and 400 monomeric species ${ }^{[46]}$. Therefore, the dominant species task of removing organic matter appears 401 to differ. In this study, it was shown that the colloidal species played the dominant role in 402 removing DON and DOC, followed by medium species and monomeric species. The decrease in 403 the level of medium species and monomeric species possibly decreased the charge neutralization 404 capacity of PAC-PDMDAAC. However, the real charge neutralization capacity increased. This 405 was attributed to the presence of the positive charge of cationic polymer. Therefore, the increase 406 of colloidal species didn't affect the charge neutralization capacity of PAC-PDMDAAC.

407

408 There was a higher reduction rate in colloidal species of PAC-PDMDAAC than in that of PAC in 409 the coagulation process. Figure $6 \mathrm{~b}$ shows the species reduction rates with a coagulant dose of 8 $410 \mathrm{mg} / \mathrm{L}$ and $16 \mathrm{mg} / \mathrm{L}$. Compared to PAC, PAC-PDMDAAC was largely reduced in the proportion 411 of colloidal species (Figure 6b) with the same dose. It had a stronger adsorption bridging of 412 organic matter because it had higher efficiency in removing DON and DOC than PAC. The 413 monomeric species and medium polymeric species in both PAC and PAC-PDMDAAC also had a 414 higher reduction of over $90 \%$. Therefore, pollutant removal should be the result of multiple 415 coagulation mechanisms. 
(a)

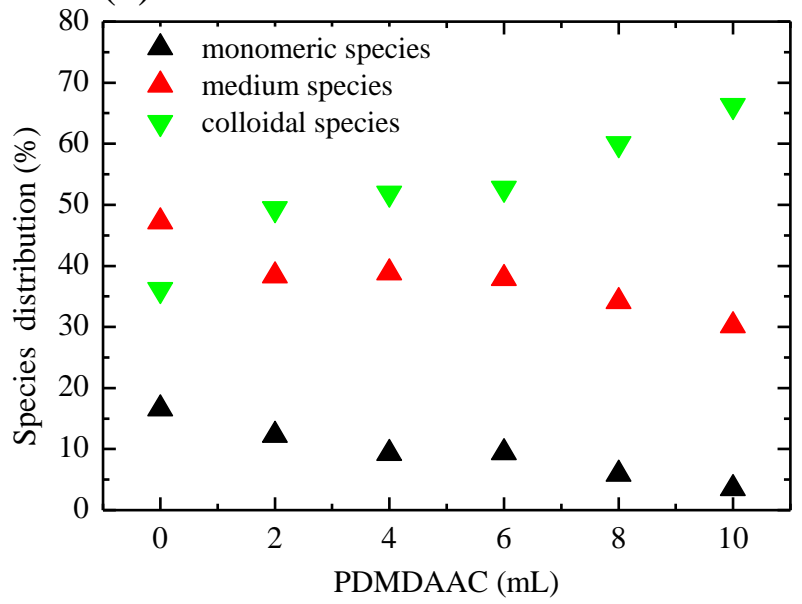

(b)

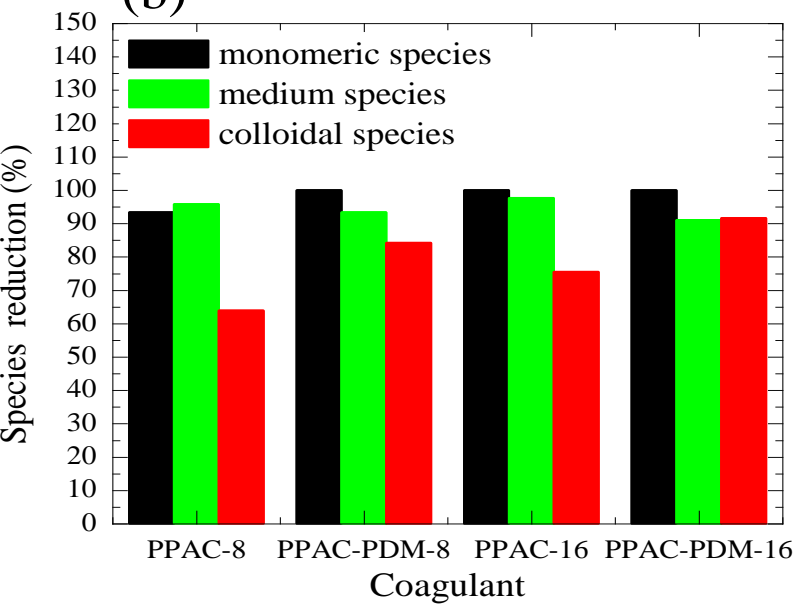

Figure 6 (a) Influence of PDMDAAC dose on species distribution and (b) species reduction by PAC and PAC-PDMDAAC at $8 \mathrm{mg} / \mathrm{L}$ and $16 \mathrm{mg} / \mathrm{L}$, respectively.

Table 2 Species distributions under different $\mathrm{pH}$ conditions.

\begin{tabular}{|c|c|c|c|c|c|c|}
\hline & $\begin{array}{l}\text { Monomeric } \\
\text { species (\%) }\end{array}$ & $\begin{array}{c}\text { Medium } \\
\text { species (\%) }\end{array}$ & $\begin{array}{c}\text { Colloidal } \\
\text { species (\%) }\end{array}$ & $\begin{array}{l}\text { Monomeric } \\
\text { species (\%) }\end{array}$ & $\begin{array}{c}\text { Medium } \\
\text { species (\%) }\end{array}$ & $\begin{array}{c}\text { Colloidal } \\
\text { species (\%) }\end{array}$ \\
\hline 4 & 24.89 & 47.50 & 27.84 & 13.95 & 38.21 & 47.83 \\
\hline 5 & 15.33 & 57.45 & 26.77 & 12.82 & 38.42 & 48.76 \\
\hline 6 & 14.66 & 61.29 & 23.57 & 10.09 & 37.54 & 52.37 \\
\hline 7 & 13.49 & 66.51 & 19.76 & 4.88 & 42.70 & 52.42 \\
\hline 8 & 13.49 & 55.42 & 30.85 & 8.68 & 38.22 & 53.09 \\
\hline 9 & 13.91 & 52.46 & 33.84 & 10.86 & 37.24 & 51.90 \\
\hline
\end{tabular}




\subsection{The influence of coagulant dose and $\mathrm{pH}$ on species reduction}

423 The species of PAC-PDMDAAC were varied in the coagulation process, which could help

424 explain the coagulation mechanisms. With PAC-PDMDAAC, the species reduction rates were 425 investigated by varying coagulant doses and the initial $\mathrm{pH}$ solution for treatment of the artificial 426 lake. The results are shown in Figure 7.

428 Figure 7 a shows the increase of species reduction rates with the increase of coagulant dose at an initial solution of $\mathrm{pH}$ 7. With a lower dose, the monomeric species reduction was generally lower

430 than for the other species; thus, DON and DOC removal was dependent on reduced proportions 431 of medium and colloidal species. Throughout the whole coagulant dose regime, the species 432 reduction rates of medium and colloidal species was higher. Monomeric species reduction 433 increased with the increased coagulant dose. The increased dose was not beneficial to the 434 reduction in DON. Therefore, the main species determined DON removal was possible, not the 435 monomeric species.

437 Figure $7 \mathrm{~b}$ shows the variation of species with the increase of $\mathrm{pH}$ at a coagulant dose of $20 \mathrm{mg} / \mathrm{L}$.

438 With the increase of $\mathrm{pH}$, the species reduction increased. Between at $\mathrm{pH} 4$ and 5, the monomeric 439 species reduction rate was higher than with other species. Therefore, the monomeric species had a 440 more significant role at lower $\mathrm{pH}$ conditions, of which reduction mostly resulted from charge 441 neutralization. At $\mathrm{pH} \mathrm{6,} \mathrm{the} \mathrm{reduction} \mathrm{rate} \mathrm{of} \mathrm{colloidal} \mathrm{species} \mathrm{began} \mathrm{to} \mathrm{increase} \mathrm{over} \mathrm{the}$ 442 reduction rate of monomeric species, which showed that floc sweeping began to react with 443 pollutants to reduce organic matter. With the increase of $\mathrm{pH}$, all of species decreased rapidly and 
444 the role of floc sweeping was increased. At $\mathrm{pH} 8$ and 9, the monomeric species and medium

445 polymeric species were most completely reduced up to over 97\%. Because of larger reduction in

446 species, the charged negative $\mathrm{Al}(\mathrm{OH})_{3}$ flocs were possible the primary products in coagulation

447 process at higher $\mathrm{pH}$ conditions.

448

(a)

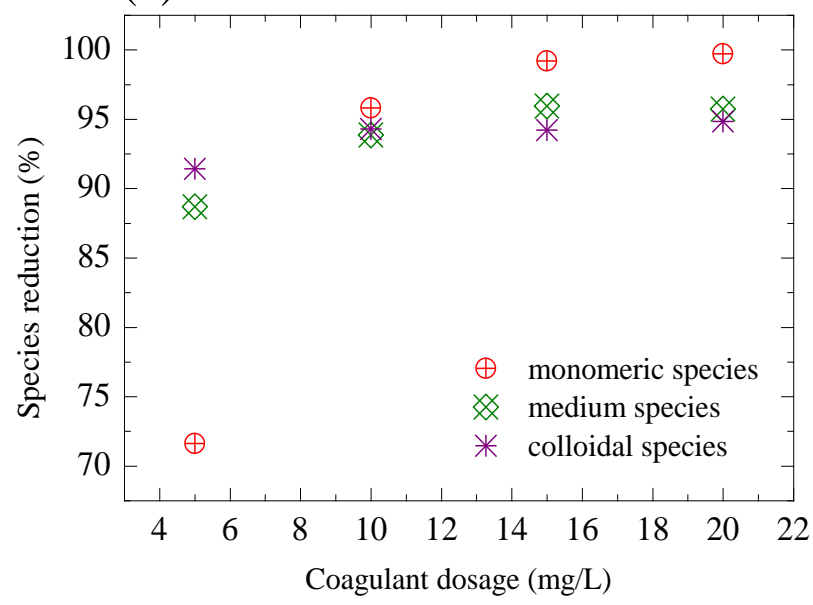

(b)

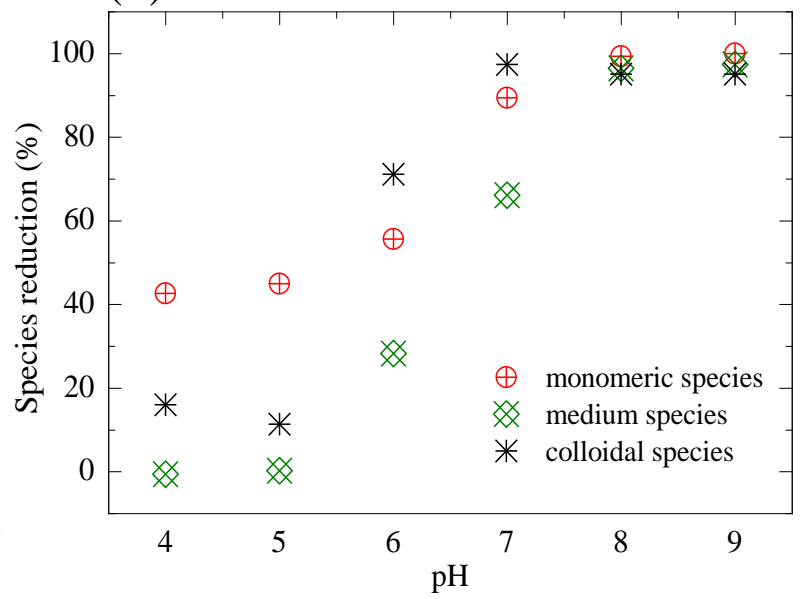

Figure 7 Species reduction rate percent by varying (a) coagulant dose and (b) pH with coagulant dose of $20 \mathrm{mg} / \mathrm{L}$. The test was performed on a sample that had not undergone restabilization.

453

\subsection{Correlation analysis}

455 The correlations of reduced coagulant species with turbidity and DOC removals were positive with the increase of coagulant dose. However, the correlations of reduced coagulant species with

457 turbidity and DON removals were negative with the increase of coagulant dose as shown in Figure 8(a-c). At a lower coagulant dose, the flocculation for DOC and turbidity was not effective, 459 and more adsorption sites for DON seemed possible. However, with the increase of coagulant 460 dose, the DOC and turbidity reduction increased and most of adsorption sites were used to absorb 461 DOC and turbidity. Less adsorption sites remained for DON, and its site amount was gradually 
462 reduced with an increased coagulant dose. DON removal was, therefore, decreased resulting in a 463 negative correlation with reduced species. The correlations of reduced species with turbidity, 464 DOC and DON removals were all positive with the increase of $\mathrm{pH}$ as shown in Figure 8(d-e). At $465 \mathrm{pH} 4-5$, the turbidity and DOC removals were lower and coagulation was mainly dependent on 466 charge neutralization. At pH 6, the DOC and turbidity removals were higher than $60 \%$. With 467 doses of $\mathrm{pH} 7-9$, almost no significant changes occurred. More colloidal adsorption sites were 468 generated when the $\mathrm{pH}$ increase caused the removal of DON. A larger transformation of 469 monomeric species and medium species to colloidal species was beneficial to the growth of 470 adsorption sites thus enhancing DON removal. The positive correlation indicated that adsorption 471 site distribution affected pollutants removal. 


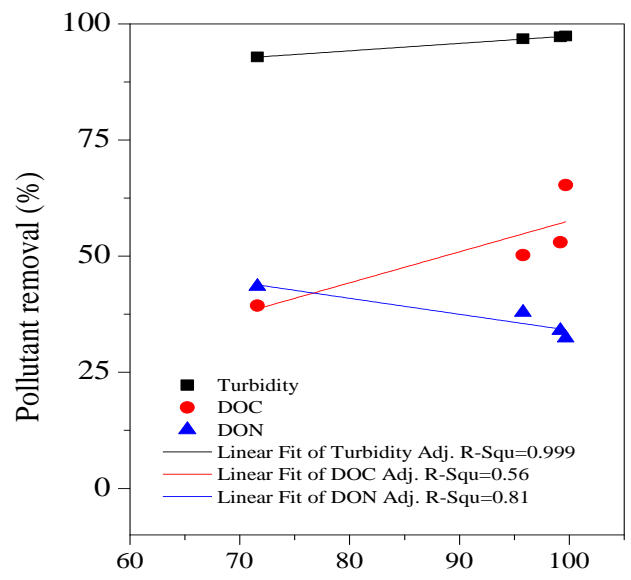

(a)

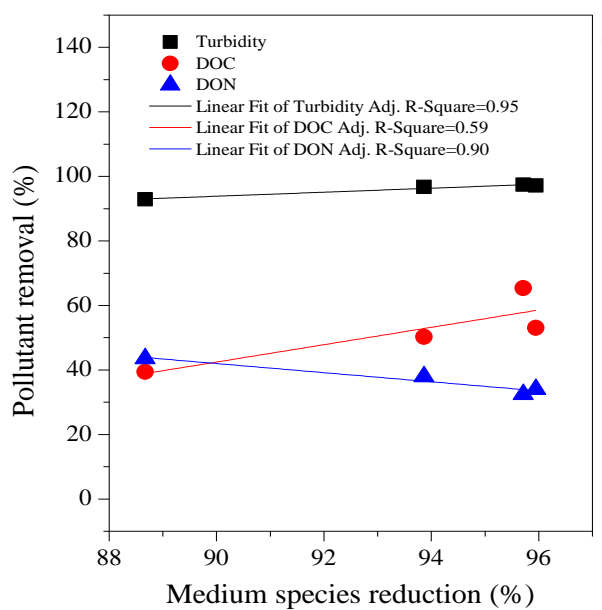

(b)

Monomeric species reduction (\%)
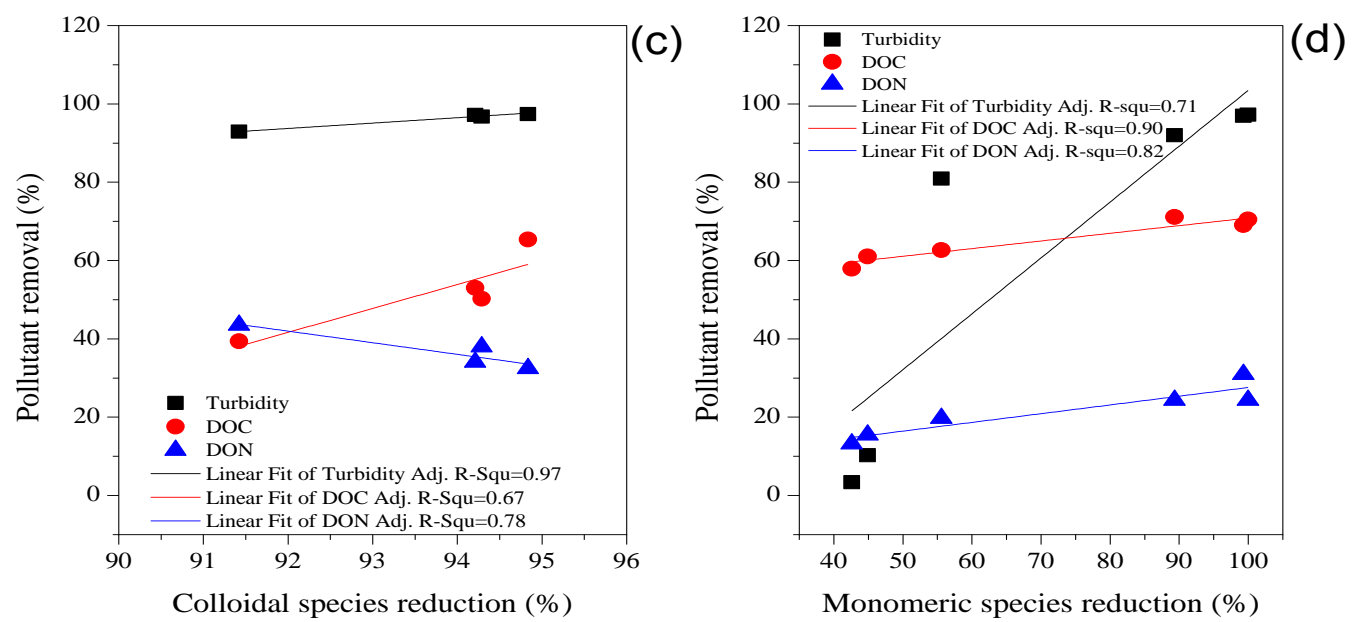

473
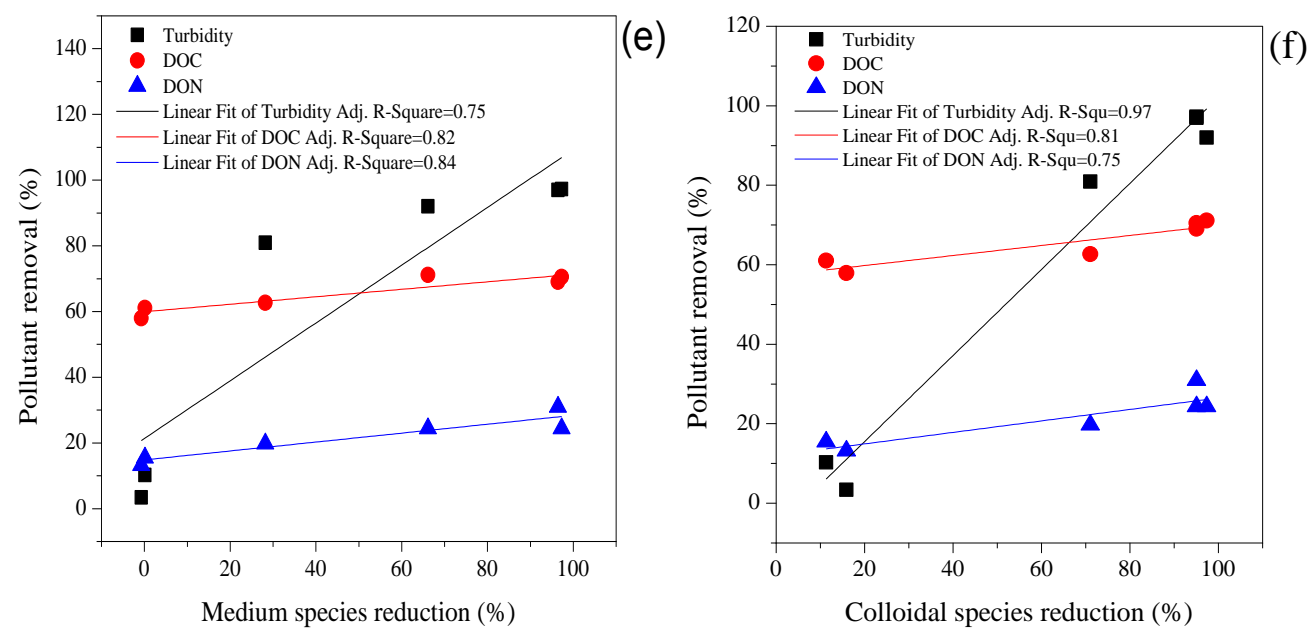

475 Figure 8 Correlation of species reductions with turbidity, DON and DOC removal rates. The data 


\section{$478 \quad 3.9$ Applicability to other types of water source}

479 The PAC-PDMDAAC can be applied to other types of water source with higher species reduction.

480 To obtain an optimum treatment of water, we used a predetermined coagulant dose to reach 481 optimum turbidity removal. All coagulations were performed at $\mathrm{pH} 8$.

482

Table 3 Applicability of PAC-PDMDAAC to different types of source water.

\begin{tabular}{|c|c|c|c|c|c|c|c|c|}
\hline Water Type & $\begin{array}{c}\text { Dose } \\
(\mathrm{mg} / \mathrm{L})\end{array}$ & $\begin{array}{c}\text { Residual } \\
\text { turbidity } \\
\text { (NTU) }\end{array}$ & $\begin{array}{c}\text { UV254 } \\
(\%)\end{array}$ & $\begin{array}{c}\text { DOC } \\
(\%)\end{array}$ & $\begin{array}{c}\text { DON } \\
(\%)\end{array}$ & $\begin{array}{l}\text { Monomeric } \\
\text { species }(\%)\end{array}$ & $\begin{array}{c}\text { Medium } \\
\text { species } \\
(\%)\end{array}$ & $\begin{array}{c}\text { Colloidal } \\
\text { species }(\%)\end{array}$ \\
\hline $\begin{array}{l}\text { Upstream } \\
\text { River }\end{array}$ & 16 & 0.25 & 62.34 & 60.86 & 24.33 & 97.00 & 96.24 & 97.26 \\
\hline $\begin{array}{l}\text { Downstream } \\
\text { River }\end{array}$ & 16 & 0.23 & 60.61 & 58.60 & 23.97 & 97.00 & 95.79 & 98.30 \\
\hline $\begin{array}{l}\text { Wetland } \\
\text { water }\end{array}$ & 24 & 0.29 & 65.68 & 60.56 & 34.41 & 93.46 & 98.03 & 99.39 \\
\hline $\begin{array}{l}\text { Wastewater } \\
\text { effluent }\end{array}$ & 24 & 0.25 & 77.65 & 71.18 & 45.76 & 96.67 & 98.27 & 98.08 \\
\hline $\begin{array}{l}\text { Artificial } \\
\text { Pool water }\end{array}$ & 24 & 1.13 & 74.60 & 70.02 & 28.68 & 93.99 & 98.73 & 96.01 \\
\hline $\begin{array}{l}\text { Natural Pool } \\
\text { water }\end{array}$ & 20 & 0.23 & 74.29 & 67.61 & 21.07 & 93.74 & 94.21 & 91.82 \\
\hline $\begin{array}{l}\text { Algal } \\
\text { solution }\end{array}$ & 16 & 0.21 & 68.12 & 62.77 & 25.15 & 93.21 & 94.66 & 91.59 \\
\hline $\begin{array}{l}\text { Artificial } \\
\text { lake water }\end{array}$ & 20 & 0.25 & 75.86 & 71.61 & 30.89 & 99.34 & 96.47 & 95.10 \\
\hline
\end{tabular}

484

485 Table 3 show that all species were almost completely removed. This indicates that PAC486 PDMDAAC interacts well with the pollutants in a wider range of aquatic environments. The 487 smallest DOC removal was reduced up to over 55\% while the largest removal was up to $71.61 \%$.

488 The smallest DON removal was reduced by slightly more than $20 \%$ and the largest removal reached $45.76 \%$. With the initial turbidity value at less than $10 \mathrm{NTU}$, the residual turbidity after 
treatment was lower than 0.3 NTU. With the initial turbidity value higher than 70 NTU, the

491 residual turbidity of modeling humic acid suspension was up to 1.14 NTU. For treatment of pool

492 water with the initial turbidity value of 32.4 NTU, the residual turbidity could be reduced up to

4931.13 NTU. An appropriate dose for turbidity removal does not imply a better removal of DON.

494 The doses that were required for better removal in turbidity and DOC were approximate and

495 DON removal was better with other specific coagulant doses.

\subsection{Fluorescence assessment on removal of DON fractions}

498 In this study, we used fluorescence spectroscopy to assess DOM fractions composition and their 499 removals by calculating the FRI values of different DOM fractions. Table 4 shows the DOM 500 fractions with different source type. These results were obtained with coagulant dose optimized 501 by assessing turbidity reduction rate. From this table, the fluorescence intensities of spectra can 502 be seen to be decreased. The fractions reductions rates were shown in Table 5. It shows that 503 aromatic protein I, aromatic protein II and soluble microbial byproduct-like, the mean reduction 504 rate $(56.47 \%)$ of soluble microbial byproduct-like was the highest. However, other two fractions 505 were reduced to a mean degree of $48.72 \%$. The effectiveness of coagulation was varied for 506 different water sources. For example, for natural pool water it showed that the aromatic protein I 507 was the mostly reduced, followed by soluble microbial byproduct-like. The mean values of 508 carbon-based species DOM fractions that were fulvic acid-like and humic acid-like were 48.07\% 509 and $50.66 \%$, which showed the similar removal degrees to that of those nitrogen-based DOM 510 fractions species (aromatic protein I, aromatic protein II). 

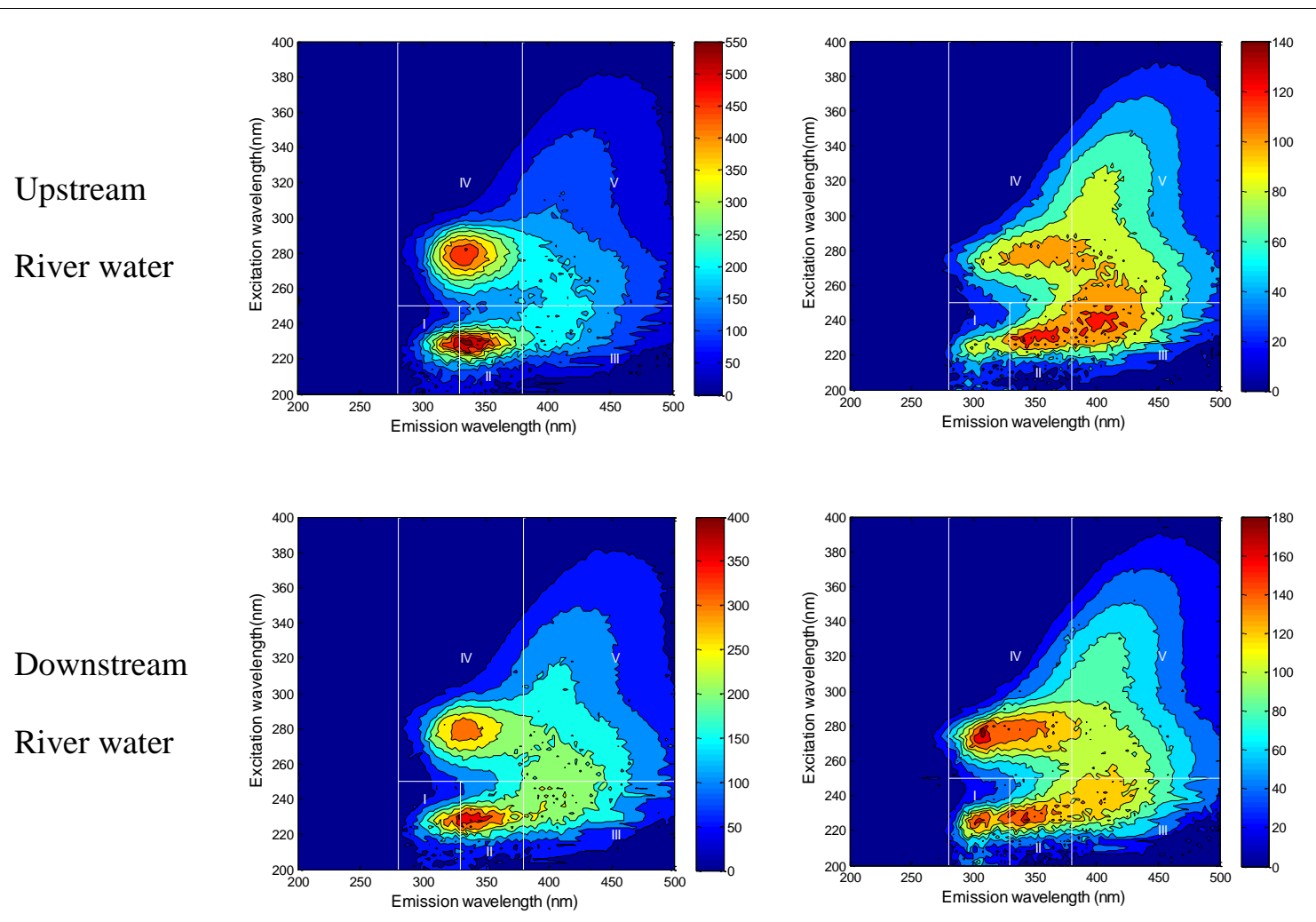

Wetland

water
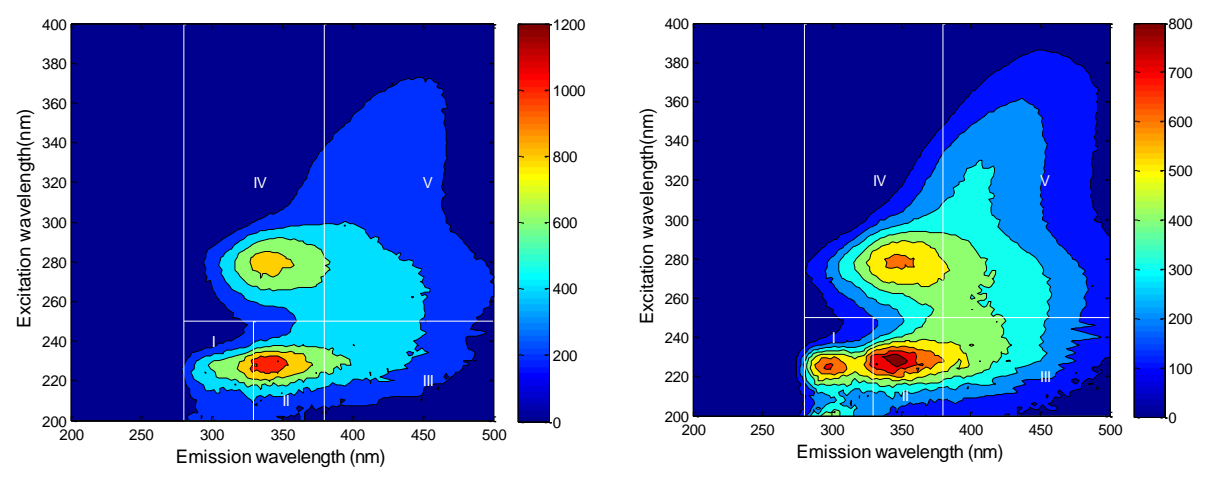

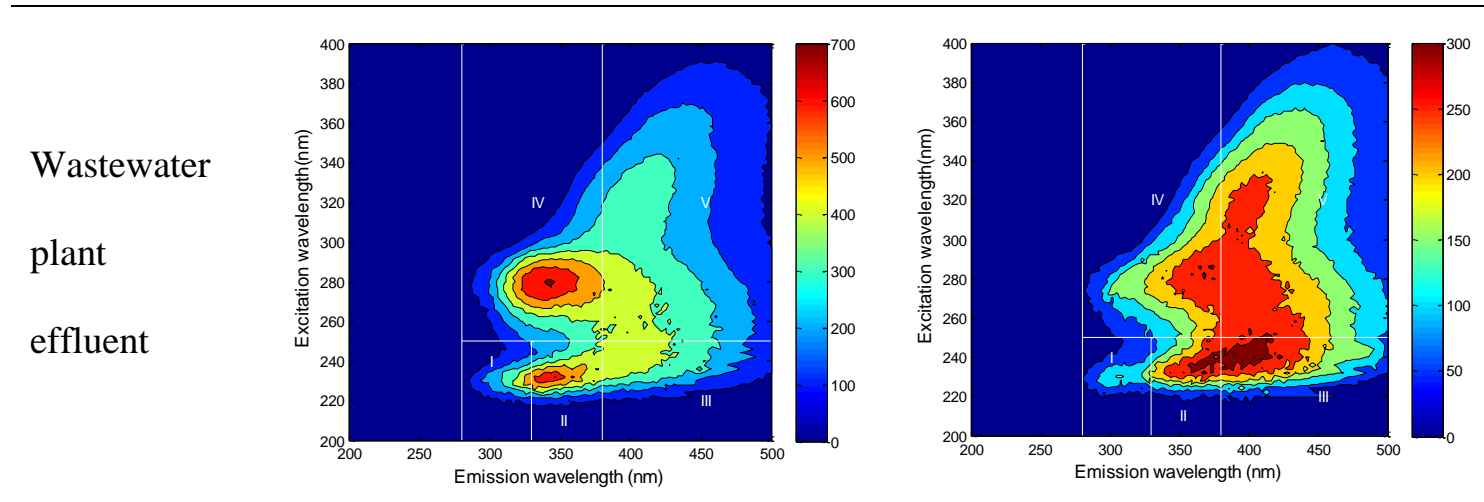

Artificial

Pool water
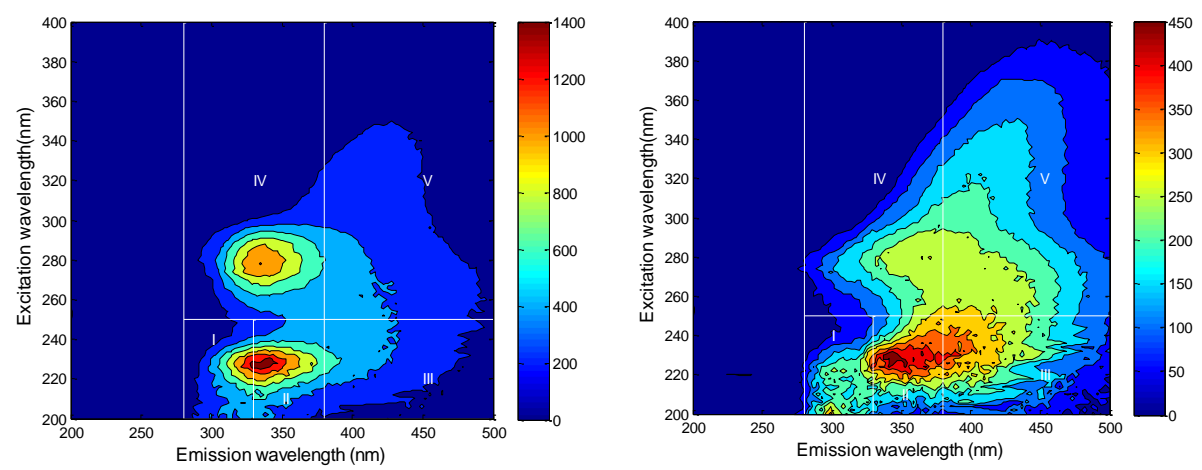

Natural pool

water
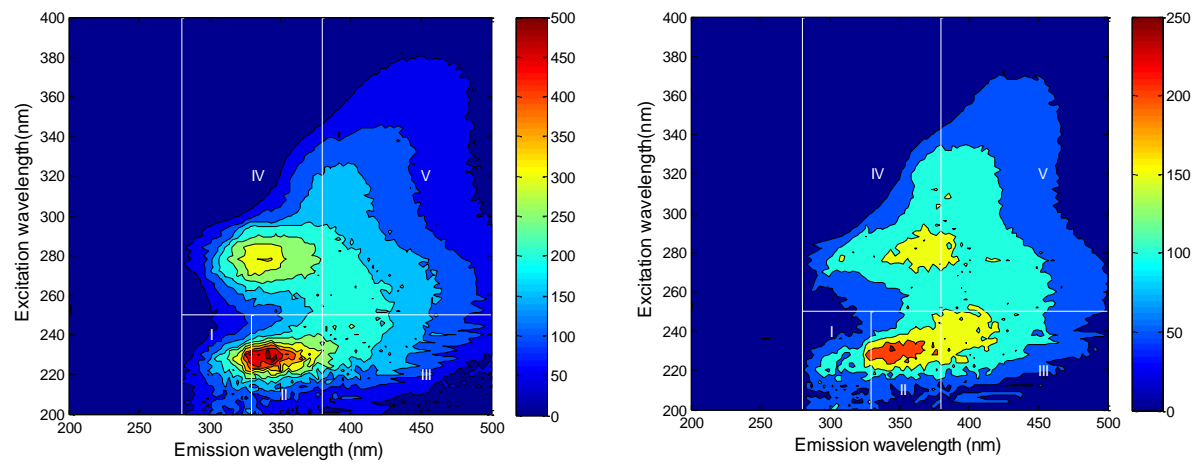

Algae

solution
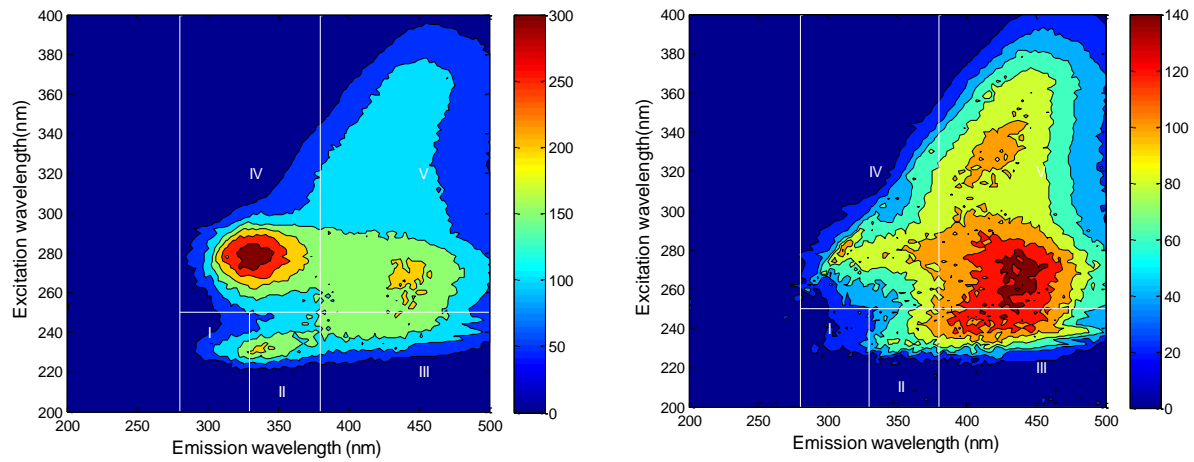
Artificial

lake water
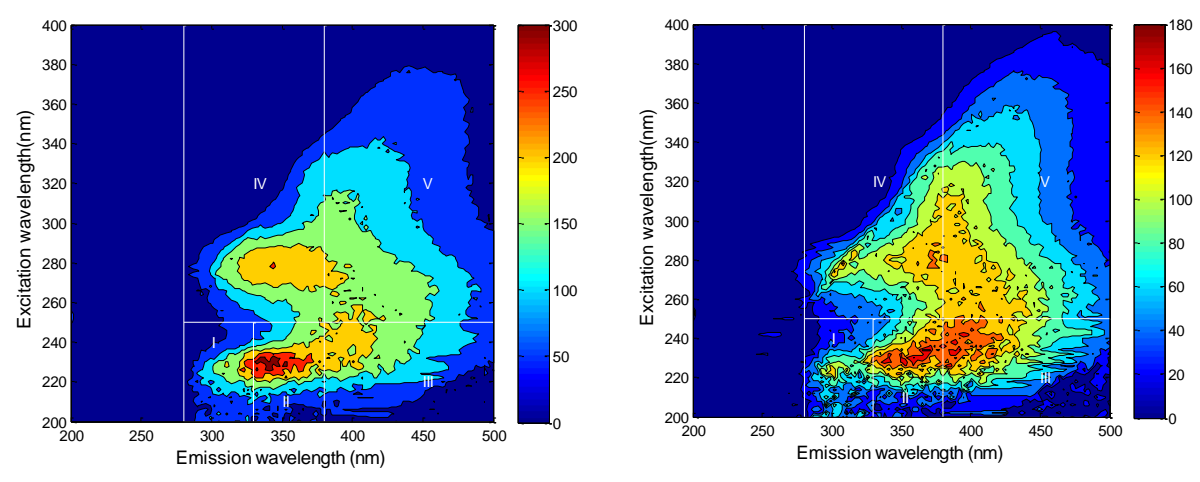

513

Table 5 DOM fractions reduction rates with different sources.

\begin{tabular}{|c|c|c|c|c|c|}
\hline No & $\begin{array}{l}\text { Aromatic } \\
\text { protein I, } \\
\quad(\%)\end{array}$ & $\begin{array}{l}\text { Aromatic } \\
\text { protein II } \\
(\%)\end{array}$ & $\begin{array}{l}\text { Fulvic acid- } \\
\text { like }(\%)\end{array}$ & $\begin{array}{c}\text { Soluble } \\
\text { microbial } \\
\text { byproduct-like } \\
(\%)\end{array}$ & $\begin{array}{l}\text { Humic acid-like } \\
\qquad(\%)\end{array}$ \\
\hline 1 & 68.40 & 68.47 & 70.05 & 75.22 & 68.34 \\
\hline 2 & 37.00 & 51.16 & 55.17 & 45.77 & 56.81 \\
\hline 3 & 8.58 & 20.71 & 32.71 & 33.75 & 38.41 \\
\hline 4 & 55.01 & 50.22 & 44.61 & 59.18 & 41.80 \\
\hline 5 & 67.10 & 57.28 & 51.21 & 68.90 & 58.05 \\
\hline 6 & 44.63 & 45.41 & 50.54 & 56.46 & 55.08 \\
\hline 7 & 69.79 & 55.33 & 37.18 & 60.16 & 34.49 \\
\hline 8 & 39.22 & 41.60 & 43.10 & 52.30 & 52.26 \\
\hline Mean & 48.72 & 48.77 & 48.07 & 56.47 & 50.66 \\
\hline
\end{tabular}

515 
517 In this study, the enhanced removal behaviors of DON and DOC by PDMDAAC in Al-based 518 coagulation with PAC were observed, and related mechanisms were revealed. With PAC519 PDMDAAC, floc settling efficiency was significantly higher than that of PAC with a higher $\mathrm{G}_{\mathrm{r}}$ 520 value of $154.99 \mu \mathrm{m} / \mathrm{min}$ and $\mathrm{R}_{\mathrm{f}}$ value of $16.27 \%$, showing a better adsorption-bridging function 521 and better recovery capacity after breakage. The cationic polymer increased the amount of

522 colloidal species thereby reducing other species amount under different $\mathrm{pH}$ conditions, which 523 required increased cationic polymer doses. The colloidal species might increase the adsorption524 bridging and floc sweeping effects of DON and DOC. Because the amounts of medium species 525 and monomeric species were decreased so the increase in charge neutralization capacity could be 526 assigned to the introduction of a cationic charge from PDMDAAC. The dominant species in 527 removal of DON and DOC were the colloidal species. The PAC-PDMDAAC presented higher 528 removal efficiency than PAC. Coagulant dose and $\mathrm{pH}$ affected DOC and DON removal: better 529 removal of DOC required a higher $\mathrm{pH}$ dose than that required for the removal of DON; the 530 increased $\mathrm{pH}$ provided more adsorption sites for removal of DON. DON and DOC removal 531 achieved the maximum at $\mathrm{pH}$ 8. All species were almost completely removed. The removal of 532 DOC, DON and turbidity reduction were dependent on multiple interactions of charge 533 neutralization, adsorption-bridging and flocs sweeping. Among them, DON and DOC removals 534 were mainly dependent on adsorption bridging and floc sweeping; turbidity removal was 535 determined by charge neutralization.

537 ACKNOWLEDGEMENTS

538 The authors gratefully acknowledge the financial support of the National Natural Science 539 Foundation of China (No. 51408215), National Natural Science Foundation of Hunan Province of 
540 China (No. 2018JJ2128), and China Postdoctoral Science Foundation funded project (No. 541 2017M622578). Andrew S. Hursthouse acknowledges the support of Hunan Provincial 542 Government and Hunan University of Science \& Technology through the High End Expert 543 Scholarship.

546 [1] J. I. Hedges, B. A. Bergamaschi, R. Benner, Mar Chem, 1993, 41, 141.

547 [2] Z. Li, C. Liu, Y. Dong, X. Chang, X. Nie, L. Liu, H. Xiao, Y. Lu, G. Zeng, Soil Till Res 2017, $166,1$.

548 [3] S. C. Bolyard, D. R. Reinhart, Waste Manage 2017, 65, 47.

549 [4] M. H. Lee, J. H. Park, E. Matzner, Geoderma 2018, 310, 163.

550 [5] G. Zhu, W. Qian, J. Yin, Z. Li, Z. Peng, B. Ren, G. Fan, W. Peng, Water Res 2016, 100, 201.

551 [6] S. Gur-Reznik, , I. Katz, , C.G. Dosoretz, Water Res 2008, 42, 1595.

552 [7] A. D. Shah, W. A. Mitch, Environ Sci Technol 2011, 46, 119.

553 [8] E. Pehlivanoglu-Mantas, D. L. Sedlak, Water Res 2008, 42, 3890.

554 [9] W. Lee, P. Westerhoff, J. P. Croué, Environ Sci Technol 2007, 41, 5485.

555 [10] E. Bei, Y. Shu, S. Li, X. Liao, J. Wang, X. Zhang, C. Chen, S. Krasner, Water Res 2016, 98, 168.

556 [11] T. C. Ng, H. Y. Ng, Water Res 2010, 44, 2336.

557 [12] Z.X. Luo, Q.S Wei, Z.H Wang, C.Y. Yan, Ecol Environ Sci 2010, 19, 45.

$558 \quad$ [13] K. Czerwionka, Oceanologia 2016, 58, 39.

559 [14] A. Aryal, Desalin. Water Treat 2016, 57, 13608.

560 [15] M. Tomaszewska, S. Mozia, Water Res 2002, 36, 4137.

$561 \quad$ [16] Y. Deng, R. Zhao, Curr Pollut Rep 2015, 1, 33.

562 [17] L. B. Guldberg, Limnol Oceanogr 2015, 47, 1712.

563 [18] J. Zhang, M. Su, B. Xi, G. Qian, J. Liu, F. Hua, S. Huo, J Environ Sci-China 2016, 50, 56.

564 [19] D.L. Sedlak, J. Jeong, H. Liu, "Uptake by Algae of Dissolved Organic Nitrogen from BNR Treatment Plant 565 Effluents" in executive summary, Iwa Publishing, Alexandria VA 2013, p. 1-2. 
B. Liu, L. Gu, X. Yu, G. Yu, H. Zhang, J. Xu, Sci Total Environ 2012, 414, 508.

[23] H. Hu, L. Ding, J. Geng, H. Huang, K. Xu, H. Ren, J Enviro Chem Eng 2016, 4, 2536.

W. Lee, P. Westerhoff, Water Res 2006, 40, 3767.

B. Liu, L. Gu, X. Yu, H. Zhang, Aqua 2012, 61, 41.

A. Matilainen, M. Vepsalainen, M. Sillanpaa, Adv Colloid Interfa 2010, 159, 189.

R. B. Gustafson, Evaluation of enhanced coagulation for the removal of dissolved organic nitrogen and the control of nitrogenous disinfection byproduct formation, Master thesis, University of North Carolina, Ann Arbor 2012, p. $i$.

C. Liu, S. He, B. Wang, J. Wang, W. Chen, Water SCI Tech-WS 2016, 16, 1432. Eng 2010, 32, 323.

P.K. Jin, Y.Y Zhang, Y.N Feng, X.C Wang, Acta Sci Circum 2013, 33, 1553.

W. Lee, P. Westerhoff, Water Res 2006, 40, 3767.

G. Li, L. Bing, Y. Xin, Science Bulletin 2010, 55, 3098.

590 [40] P. C. Wen, Chemosphere 2002, 47, 963.

591 [41] X. Bo, B. Gao, N. Peng, Y. Wang, Q. Yue, Y. Zhao, Chem Eng J 2011, 173, 400. 
593 [43] Q. Chang, Fu, J.Y., Li, Z.L., "Principles of Flocculation", Lanzhou University Press, 2rd edition, Lanzhou 2001, p. 1-258.

595 [44] Z. Yang, B. Liu, B. Gao, Y. Wang, Q. Yue, Sep Sci Technol 2013, 111, 119.

596 [45] M. Sadrnourmohamadi, B. Gorczyca, Sep Sci Technol 2015, 50, 2075.

597 [46] M. Yan, D. Wang, J. Qu, W. He, C. W. K. Chow, J Colloid Interf Sci 2007, 316, 482. 